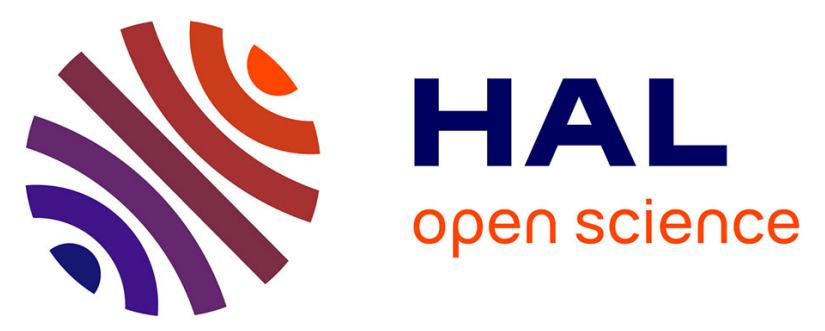

\title{
Enzymatic hydrolysis of corn crop residues with high solid loadings: New insights into the impact of bioextrusion on biomass deconstruction using carbohydrate-binding modules
}

Etienne Gatt, Vinay Khatri, Julien Bley, Simon Barnabé, Virginie

Vandenbossche, Marc Beauregard

\section{To cite this version:}

Etienne Gatt, Vinay Khatri, Julien Bley, Simon Barnabé, Virginie Vandenbossche, et al.. Enzymatic hydrolysis of corn crop residues with high solid loadings: New insights into the impact of bioextrusion on biomass deconstruction using carbohydrate-binding modules. Bioresource Technology, 2019, 282, pp.398-406. 10.1016/j.biortech.2019.03.045 . hal-02625594

\section{HAL Id: hal-02625594 \\ https://hal.inrae.fr/hal-02625594}

Submitted on 22 Oct 2021

HAL is a multi-disciplinary open access archive for the deposit and dissemination of scientific research documents, whether they are published or not. The documents may come from teaching and research institutions in France or abroad, or from public or private research centers.
L'archive ouverte pluridisciplinaire HAL, est destinée au dépôt et à la diffusion de documents scientifiques de niveau recherche, publiés ou non, émanant des établissements d'enseignement et de recherche français ou étrangers, des laboratoires publics ou privés.

\section{(ㄷ)(1) $\$$}

Distributed under a Creative Commons Attribution - NonCommerciall 4.0 International 


\section{Enzymatic hydrolysis of corn crop residues with 2 high solid loadings: new insights into the impact of 3 bioextrusion on biomass deconstruction using 4 carbohydrate-binding modules}

5

6 7

Etienne Gatt ${ }^{\mathrm{a}, 1^{*}}$, Vinay Khatri ${ }^{\mathrm{b}, \mathrm{d}^{*}}$, Julien Bley ${ }^{\mathrm{c}, \mathrm{e}}$, Simon Barnabé ${ }^{\mathrm{c}}$, Virginie Vandenbossche ${ }^{\mathrm{a}}$, Marc Beauregard ${ }^{\mathrm{c}, \mathrm{d}}$

${ }^{\text {a }}$ Laboratoire de Chimie Agro-industrielle, LCA, Université de Toulouse, INRA, Toulouse, France.

${ }^{\mathrm{b}}$ Department of Agricultural, Food and Nutritional Science, University of Alberta, Edmonton, AB T6G 2P5, Canada

${ }^{\mathrm{c}}$ Centre de recherche sur les matériaux lignocellulosiques, Université du Québec à Trois-

Rivières.

d PROTEO, Université Laval, Québec G1V 4G2, Canada

e Innofibre, 3351 Boulevard des Forges, Québec G9A 5E6, Canada

${ }^{*}$ Contributed equally to this work

\section{Abstract}

Lignocellulosic biomass is a sustainable source of renewable substrate to produce low carbon footprint energy and materials. Biomass conversion is usually performed in two steps:

a biomass pretreatment for improving cellulose accessibility followed by enzymatic hydrolysis of cellulose. In this study we investigated the efficiency of a bioextrusion pretreatment (extrusion in the presence of cellulase enzyme) for production of reducing sugars

${ }^{1}$ Corresponding author at: Université de Toulouse, INP, Laboratoire de Chimie

Agro-Industrielle, ENSIACET, 4 Allée Emile Monso, BP 44362, 31030 Toulouse Cedex

4, France. Tel.: +33 5343235 14; fax: +33 534323599 .

E-mail address: etienne.gatt@ensiacet.fr (E. Gatt); virginie.vandenbossche@ensiacet.fr (V. Vandenbossche) 
from corn crop agricultural residues. Our results demonstrate that bioextrusion increased the reducing sugar conversion yield by at least $94 \%$ at high solid/liquid ratio (14\% to $40 \%$ ).

Monitoring biomass surface with carbohydrate-binding modules (FTCM-depletion assay) revealed that well known negative impact of high solid/liquid ratio on conversion yield is not due to lack of exposed cellulose, which was abundant under such conditions. Bioextrusion was found to be less efficient on alkaline pretreated biomass but being a mild and solvent limiting pretreatment, it might help to minimize the waste stream.

\section{Keywords}

Lignocellulosic biomass, bioextrusion, carbohydrate-binding modules, enzymatic hydrolysis, FTCM, FTCM-depletion assay

\section{Introduction}

Lignocellulosic biomass (LCB) is a sustainable, renewable, abundant and inexpensive substrate. Its valorization can lead to the production of energy and materials with a low carbon footprint. LCB has been identified as a possible solution to the current energy crisis, characterized by depletion of fossil resources and a pressing need for reduced $\mathrm{CO}_{2}$ emissions (Lynd, 2017). However, the use of LCB as a substrate for $2^{\text {nd }}$ generation bioethanol production is hampered by its complex structure and recalcitrance to enzyme actions (Himmel et al., 2007). To overcome this limitation, biomass conversion is usually performed in two steps: the first step involves a biomass pretreatment for improving cellulose accessibility, which is followed by enzymatic hydrolysis of cellulose (Himmel et al., 2007; Sun and Cheng, 2002; Khatri et al., 2018a).

The main objective of pretreatments for subsequent biochemical conversion is to increase access to cellulose (also known as cellulose accessibility), which can later be hydrolyzed by enzymatic hydrolysis processes (Khatri et al., 2018a). Twin screw extrusion has been frequently used as the pretreatment of LCB (Karunanithy and Muthukumarappan, 2013). 
Extrusion pretreatment has many advantages including high shear, rapid heat transfer, and effective and rapid mixing afforded by good modulation of treatment steps (Vandenbossche et al., 2014). The use of biocatalyst during the extrusion process could improve the biocatalysts impregnation to biomass and boost the subsequent batch saccharification step. Therefore, in an attempt to improve the biocatalysts impregnation, the enzymes were injected during the extrusion process (Duque et al., 2014; Vandenbossche et al., 2015, 2014). This novel and short bioreactive process, named bioextrusion (a mechano-enzymatic pretreatment), has been proven to enhance the enzymatic hydrolysis of the LCB, as summarized by Gatt et al., 2018; Vandenbossche et al., 2015.

One of the key advantages of the bioextrusion process is its ability to work with high substrate loading. This is a critical parameter in order to decrease water consumption and the costs associated with its removal (Lin and Tanaka, 2006). However, high solid loading often decreases hydrolytic efficiency (Ramachandriya et al., 2013). In-depth studies about high solid loadings suggest that low agitation efficiencies, reduction of the contact area between enzymes and substrates, loss of enzymatic activities and non-specific adsorption are some of the factors associated with decrease in hydrolytic efficiency (Ramachandriya et al., 2013). Other conditions can also decrease biomass hydrolysis, such as inhibition of enzymes by reaction products and mass transfer limitations (Hodge et al., 2008; Kim et al., 2008). Therefore, it is important to study the bioextrusion process parameters in great detail in order to cost-effectively maximize the saccharification of the cellulose and hemicellulose components to fermentable sugars.

The main objective of any pretreatment, including bioextrusion, is to improve the subsequent enzymatic hydrolysis of the holocellulose fraction by increasing the access of enzymes to cellulose (also known as cellulose accessibility to enzymes) (Lynd et al., 1999; Wyman, 2013, Khatri et al., 2018a). However, pretreatments vary greatly in the way they help 
to expose cellulose and other components. Contrary to other pretreatment methods which uses intensive physical and/or chemical conditions, bioextrusion is a mild mechano-enzymatic pretreatment technique because it requires less energy and water consumption (Vandenbossche et al., 2014). The combination of mechanical and biochemical constraints is believed to overcome limitations associated with high solid and enzymes loadings (Gatt et al., 2018). Currently, our incomplete understanding about the impact of pretreatment (on microstructure) on a particular biomass is believed to be a key issue for reducing costs associated with bioenergy production (Rollin et al., 2011; Zhang and Lynd, 2006; Khatri et al., 2018a). Therefore, is it important to study the effectiveness and impact of pretreatments on a biomass substrate that may play a significant role in a commercial viability of bioenergy production. One of the major difficulties in studying pretreatment and process parameters is the lack of rapid, high throughput and reliable tools for monitoring and/or tracking lignocellulosic polymers at the biomass surface (DeMartini et al., 2013; Khatri et al., 2016). Recently, a rapid and low-cost method has been developed to directly and precisely monitor the surface of wood fibers and agricultural LCB using selected carbohydrate-binding modules (CBMs). Named "fluorescent protein-tagged carbohydrate-binding modules method" (FTCM) this method, and its adaptation FTCM-depletion assay (Khatri et al., 2018a), relies on the use of four specific ready-to-use probes made of recombinant CBMs genetically linked to a designated fluorescent protein of the green fluorescent protein (GFP) family (Hébert-Ouellet et al., 2017; Khatri et al., 2018a, 2018b, and 2016). The FTCM and FTCM-depletion assay have been extensively studied and shown as robust, rapid, easy to use, unambiguous and costeffective surface characterization methods (Khatri et al., 2018a, 2018b, and 2016; HébertOuellet et al., 2017; Bombeck et al., 2017). Therefore, the use of this surface characterization method for studying the impact of various pretreatments (bioextrusion and alkaline pretreatment) on fiber microstructure provokes substantial interest. 
The aim of this work is to study the influence of bioextrusion on a subsequent batch hydrolysis of LCB at high solid to liquid (S/L) ratios. In addition, this study also describes the use of carbohydrate-binding modules to understand the influence of bioextrusion on cellulose accessibility. Raw (RC) and alkaline pretreated corn crop residues (PC) were hydrolyzed in batch conditions for $48 \mathrm{~h}$ using a cellulolytic cocktail and different substrate concentrations (S/L ratios from 14 to $40 \%$ ), with or without a previous bioextrusion step. A number of analyses were performed in order to further our understanding of the impact of bioextrusion and various experimental parameters on corn crop residues and its subsequent enzymatic hydrolysis.

\section{Materials and methods}

\subsection{Biomass: preparation and pretreatments}

Raw corn (RC) crop residues (Zea mays L.) provided by Ferme Olivier and Sebastien

Lépine of Agrosphere Co. (Québec, Canada) were used in this study. Corn crop residue was a mixture of lightly ground cobs, stover and leaves. The entire mixture was milled together to produce a working sample with particle sizes lower than $5 \mathrm{~mm}$.

Raw corn (RC) stover residues were also pretreated by cooking in $\mathrm{NaOH}$ solution under pressure in a laboratory digester provided by M/K Systems Inc. (Danver, MA, USA). The digestion conditions were as follows: a liquor ratio of $5(12 \% \mathrm{NaOH} / \mathrm{g}$ of residue $) ; 175{ }^{\circ} \mathrm{C} ; 60$ min digestion period as described by Adjalle et al., 2017. The alkaline pretreated corn (PC) was later washed with a $\mathrm{pH} 4.5$ citrate buffer $(50 \mathrm{mM})$ and dried at $50^{\circ} \mathrm{C}$ for $48 \mathrm{~h}$. This pretreatment removes a significant portion of the hemicelluloses and lignins, producing a less complex starting material that exhibits an increased enzymatic accessibility (Khatri et al., 2018a).

\subsection{Enzyme cocktail}

Enzymatic saccharification was carried out using the ACCELLERASE® DUET cocktail from DuPont Industrial Biosciences in a citrate buffer $(50 \mathrm{mM}, \mathrm{pH} 4.5)$. The enzymatic 
cocktail had a protein content of $87.8 \mathrm{mg} / \mathrm{ml}$ and a cellulases activity of $115.6 \mathrm{FPU} / \mathrm{mL}$.

125 According to the supplier's specification the ACCELERASE enzyme cocktail is expected to have significant accessory enzymes (xylanase) activity. The protein content was measured with the total protein micro Lowry kit (with Peterson's modification) from Sigma-Aldrich.

The cellulase activity was measured according to Ghose, 1987. The enzymatic cocktail had an optimum temperature of $50^{\circ} \mathrm{C}$ and an optimum $\mathrm{pH}$ of 4.5 .

\subsection{Bioextrusion}

Bioextrusion was carried out using a $27 \mathrm{~mm}$ twin-screw extruder (Entek, OR, US). Raw or alkaline pretreated corn residues were introduced to the enzymatic cocktail and citrate buffer (to control the $\mathrm{S} / \mathrm{L}$ ratio) as indicated in Figure 1 . Extrusions were performed at $50^{\circ} \mathrm{C}, 125$ rpm and the residence time was 5 minutes. The screw configuration was chosen according to the typical bioextrusion screw configuration as described elsewhere (Vandenbossche et al., 2015, 2014; Duque et al., 2014; Gatt et al., 2018). Alternating between transport areas (T)

137 (conveying elements) and intensive mixing areas with kneading blocks (M) promoted both good mixing conditions and isolated areas for reactions to occur (Figure 1). All the operating conditions used here have previously been optimized by Duque et al., 2014; Vandenbossche et al., 2015, 2014. The temperature used here was optimum for the enzymatic hydrolysis. The

141 screw rotation speed of $125 \mathrm{rpm}$ was used to provide the longest residence time possible for

142 the enzyme incubation. The original objective of the bioextrusion was to start the enzymatic hydrolysis in the extrusion pretreatment step, taking advantage of the good impregnation capacities that extrusion has to offer.

Figure 1: Bioextrusion screw configuration. T corresponds to transport areas with conveying elements and $M$ are mixing zones with kneading blocks. Ex corresponds to the bioextrudated biomass. Numbers 148 in first row indicate the pitch of the screws or the angle between the kneading blocks. Numbers in the 149 second row indicate the length of the screw in $\mathrm{mm}$. 


\subsection{Enzymatic hydrolysis}

Enzymatic hydrolysis were performed in $50 \mathrm{~mL}$ tubes with $50 \mathrm{mM}$ citrate buffer (pH 4.5), $0.1 \%$ sodium azide, and $0.5 \mathrm{~mL}$ enzymatic cocktail per g of cellulose (Danisco US Inc., 2007). Tubes were placed in an Ecotron ${ }^{\circledR}$ incubation shaker at $50^{\circ} \mathrm{C}$ and $200 \mathrm{rpm}$. Treatments with raw corn and without previous bioextrusion are noted as RC-E; treatments with raw corn and with previous bioextrusion are named as RC-XE; treatments with alkaline pretreated corn and without previous bioextrusion are titled as PC-E; and treatments with alkaline pretreated corn and with previous bioextrusion are abbreviated as PC-XE. These experimental conditions are schematically represented in Figure 2.

Moisture content is one of the most influencing factors for optimal biomass saccharification as described in most of the previous bioextrusion studies (Chouvel et al., 1983; Gatt et al., 2018; Govindasamy et al., 1997 Vandenbossche et al., 2015, 2014).

Therefore, its impact was tested by varying the substrate loading. This parameter is expressed as the ratio of grams of solid per $100 \mathrm{~g}$ of liquid (S/L ratio). Non-bioextrudated and bioextrudated raw corn (RC-E and RC-XE) were prepared with four different S/L ratios, 14\% $( \pm 0.04 \%), 23 \%( \pm 1.00 \%), 31 \%( \pm 0.72 \%)$, and $40 \%( \pm 0.35 \%)$. Non-bioextrudated and bioextrudated alkaline pretreated corn (PC-E and PC-XE) were prepared with two different S/L ratios, $14 \%( \pm 0.50 \%)$ and $31 \%( \pm 1.91 \%)$. For PC-E and PC-XE, the S/L ratio of $14 \%$ was selected because it corresponds to the enzymes supplier's recommendations and $31 \%$ because it allows to evaluation of the influence of a higher substrate loading, without clear process limitations observed with $40 \%$ in RC-E and RC-XE. Reactions were stopped by immersing the tubes in boiling water for $5 \mathrm{~min}$ and then cooled in an ice bath for 5 minutes. Each experimental condition was carried out in triplicate in separate tubes.

Figure 2: Schematic representation of the experimental and analytical parts. RC, raw corn; $P C$, alkaline pretreated corn. XE, batch hydrolysis with previous bioextrusion step; E, batch hydrolysis without previous bioextrusion step; B, batch hydrolysis process. Path 1: samples diluted to $5 \%$ of dry content. Path 2: Non-diluted samples. 


\subsection{Analytical methods}

\subsubsection{Dry matter and parietal compounds}

Moisture content was determined according to the French standard procedure NF V

03-903. A relative proportion of each of the three parietal constituents (cellulose, hemicelluloses, and lignins) contained in the solids was measured using the ADF-NDF method (Van Soest and Wine, 1968). All determinations were carried out in triplicate.

\subsubsection{Sugars analysis}

Tube content (Figure 2, path 1) was diluted with distilled water in order to reach $5 \%$ of dry matter and was centrifuged at $5,000 \mathrm{~g}$ for $10 \mathrm{~min}$ at $20^{\circ} \mathrm{C}$. The reducing sugars in the supernatant were determined using the DNS method (Miller, 1959). The quantity of reducing sugars was used to calculate the rate of holocellulose deconstruction $\left(r_{H D}\right)$. It is expressed as the ratio of reducing sugars in the sample, measured in terms of glucose equivalents, over the initial mass of holocellulose. Results were corrected with blank values obtained at $t=0 \mathrm{~h}$ without bioextrusion. However, as this method titrates all the reducing functions of the different sugars in solution (e.g. oligosaccharides, pentose, hexoses etc.), specific glucose concentration was also measured using high performance liquid chromatography (HPLC). HPLC analysis were carried out with a Rezex RHM-Monosaccharide with deionized water as the eluent in isocratic mode, with a flow rate fixed at $0.6 \mathrm{~mL} / \mathrm{min}$. Column was kept at $85^{\circ} \mathrm{C}$ and RI detector at $50^{\circ} \mathrm{C}$ (Sluiter et al., 2010).

\subsubsection{Particle size distribution}

After $48 \mathrm{~h}$ of enzymatic hydrolysis, the samples were washed with distilled water and filtered through glass fiber Whatman $934 \mathrm{AH}$ filters. These filters have a porosity of $1.5 \mu \mathrm{m}$. Retained solids were then dried at $103^{\circ} \mathrm{C}$ during $12 \mathrm{~h}$ prior to mass measurements. Dry matter left after filtration was compared to the initial dry matter in order to calculate the proportion of dry solid with particle size smaller than $1.5 \mu \mathrm{m}\left(p_{\emptyset \leq 1.5} \mu \mathrm{m}\right)$.

$$
p_{\emptyset \leq 1.5 \mu m}=\frac{m_{d t}-m_{d f}}{m_{d t}}
$$


$m_{d t}:$ dry mass before filtration

$m_{d f}:$ residual dry mass after filtration

\subsubsection{Cellulose accessibility (surface cellulose exposure) using} FTCM-depletion assay

After $48 \mathrm{~h}$ of enzymatic hydrolysis, the unhydrolyzed residues were filtered, dried and grounded. FTCM-depletion assay was used on these unhydrolyzed solid residues in order to detect the total cellulose accessibility or surface cellulose (both crystalline and amorphous cellulose) exposure after the various chemical, mechanical and enzymatic treatments described above. The tracking assay was performed as described by Khatri et al., 2018a with two different FTCM probes: eGFP-CBM3a (GC3a) specific to crystalline cellulose and eCFPCBM17 (CC17) specific to amorphous (non-crystalline) cellulose. Probe production and characterization (spectroscopic maxima, affinity to related substrate, and discrimination among substrates) were described in earlier reports (Hébert-Ouellet et al., 2017; Khatri et al., 2018a, 2018b, and 2016; Bombeck et al., 2017). Fluorescence measurements were recorded at room temperature using a Synergy Mx microplate reader (BioTek). Fluorescence values were further converted into $\mu \mathrm{mol}$ of fluorescent probes per $\mathrm{g}$ of dry biomass, using the appropriate fluorescence standard curves for each probe. FTCM-depletion assay allows to specifically measure the crystalline and amorphous cellulose exposure at the surface of the biomass (Khatri et al., 2018a).

\section{Results and discussion}

\subsection{Biomass characterization}

Figure 3 represents biomass composition characterization of raw (RC) and alkaline pretreated corn (PC). 
The alkaline pretreatment led to the removal of a significant part of the extractives

231 such as proteins, starches, pectins, tannins present in the raw biomass (Sluiter et al., 2010). In

addition, the alkaline action also induces the solubilization of most of the lignins and

hemicelluloses fractions. The amount of lignin in the RC biomass was $10.9 \%$, which is similar

to the earlier published reports on identical biomass (Adjalle et al., 2017, Khatri et al., 2018a).

The alkaline pretreatment reduced the amount of lignin by $\sim 65 \%$ which is compatible with

236 the known effect of alkaline pretreatment (Adjalle et al., 2017, Khatri et al., 2018a).

237 Furthermore, the total cellulose content (detected by ADF-NDF protocol) was significantly

238 increased $(\sim 78 \%)$ by alkaline pretreatment (Figure 3 ) which is in accordance with the known

239 impact of this widely used pretreatment technique (Kim et al., 2016). The alkaline pretreated

240 biomass was a mixture of relatively less colored, swollen and broken fibers, which is

241 compatible with a decreased content of colored lignin.

The main objective of pretreatment for subsequent biochemical conversion is to

243 increase access to cellulose (also known as cellulose accessibility) by removing most of the

244 lignin and hemicelluloses. From total composition analysis (ADF-NDF analysis; Figure 3),

245 one can reasonably infer that more cellulose will become available at the fiber surface when

246 lignin and/or hemicelluloses are partially removed from biomass. However, such an

247 interpretation of pretreatment impact is indirect as total composition analysis represents a bulk

248 analysis and does not interrogate fiber surface properties (such as cellulose accessibility)

249 (Khatri et al., 2018a).

The surface exposure or surface accessibility of lignocellulosic polymers is an

251 important substrate characteristic that influences the enzymatic hydrolysis rates (Arantes and

252 Saddler, 2010; Hong et al., 2007; Mansfield et al., 1999; Zhang and Lynd, 2004). A recent

253 study using FTCM-depletion assay probes reported that enzyme access to cellulose (total

254 cellulose surface accessibility) was a determinant for saccharification yield (Khatri et al. 
2018a). Therefore, FTCM-depletion assay was used in this study to specifically detect the

256 proportion of the surface exposed crystalline and amorphous cellulose at the fiber surface of raw and pretreated biomasses.

Figure 4 represents the surface exposure or surface accessibility of cellulose in raw (RC) and pretreated (PC) corn crop residues (before enzymatic hydrolysis). Results show that the amount of bound FTCM probes $(\mu \mathrm{mol})$ per gram of biomass (which depends on their cognate lignocellulosic component(s) surface exposure or surface accessibility) has increased after the alkaline pretreatment step. When comparing to $\mathrm{RC}$ crop residues, the total cellulose exposure (GC3a $+\mathrm{CC} 17$ probes binding) or total cellulose surface accessibility of PC crop residues increased 2-fold (Figure 4A). The increase in total cellulose exposure (GC3a + CC17 probes binding) on the fiber surface is accompanied by the $2.01 \pm 0.09$-fold increase in crystalline cellulose (GC3a probe binding) and $2.30 \pm 0.07$-fold increase in amorphous cellulose (CC17 probe binding) (Figures 4B and C). This indicates that the surface accessibility of cellulose has increased after the alkaline pretreatment. Furthermore, the increase of the amorphous cellulose exposure was slightly higher than the increase of the crystalline cellulose exposure (Figures 4B and C). One explanation of this difference involves the well-known negative impact of the alkaline pretreatment on cellulose crystallinity (Fan et al., 1987; Sun and Cheng, 2002). The increase in the surface accessibility of cellulose or

273 FTCM probe binding can also be relate to the Brunauer-Emmett-Teller (BET) surface area of

274 the biomass. Several studies have suggested that alkaline pretreatment is expected to increase 275 the surface area of fibers (Boonsombuti et al., 2013; Kim et al., 2014; Lee et al., 2015; Song et al., 2016) which might reflect the increased binding of FTCM probes. These results are also 277 compatible with the expected impact of similar alkaline pretreatment on corn crop residues 278 (Khatri et al.et al., 2018a). 
Figure 4: Surface exposure of A) total cellulose, B) crystalline cellulose and C) amorphous cellulose before and after alkaline pretreatment as monitored by FTCM-depletion assay. Error bars represent the standard deviation.

\subsection{Biomass deconstruction}

3.2.1. Sugar conversion rates and biomass fractionation As mentioned previously, the increase in total cellulose accessibility is expected to enhance the subsequent hydrolysis efficiency. The impact of different treatments on production of reducing sugars (Figure 5A), glucose production yield (Figure 5B) and biomass fractionation (Figure 5C) are presented in Figure 5.

Figure 5: A) impact of $S / L$ ratio on reducing sugar conversion rates after $48 \mathrm{~h}$ of enzymatic hydrolysis. $r_{H D}$ is the rate of holocellulose deconstruction (or reducing sugars conversion), expressed as grams of glucose equivalents per 100 grams of holocellulose into the initial biomass. B) glucose production yield (\% of theoretical), after 48 h enzymatic hydrolysis. C) fraction of total dry biomass smaller than $1.5 \mu \mathrm{m}$ after $48 \mathrm{~h}$ of enzymatic hydrolysis. $R C$-E, raw corn without a previous bioextrusion step; $R C$-XE, raw corn with a previous bioextrusion step; $P C$-E, alkaline pretreated corn without bioextrusion; $P C-X E$ alkaline pretreated corn with previous bioextrusion. Error bars represent the standard deviation. 
In all cases, increasing solid concentration led to a gradual decline in the holocellulose

hydrolysis. In particular, increasing the S/L ratio from $14 \%$ to $40 \%$ led to a $42 \%$ and $25 \%$

decrease in the reducing sugars production for non-bioextrudated (RC-E) and bioextrudated

(RC-XE) raw corn, respectively (Figure 5A). In addition, the S/L ratio increment led to a $47 \%$ and a 52\% decrease in the final glucose production yield for RC-E and RC-XE, respectively

(Figure 5B). In the case of PC, no significant differences between non-bioextrudated (PC-E)

and bioextrudated (PC-XE) biomasses were observed. Reducing sugar production and glucose production yield dropped by at least $36 \%$ and $35 \%$, respectively, when increasing the S/L ratio from $14 \%$ to $31 \%$. Due to the resource limitations only two conditions of the S/L ratio were used in the case of PC. Therefore, one has to be careful while making any strong and critical interpretation in case of the PC biomass. Regardless, these results clearly demonstrate the negative influence of solid loadings on reducing sugar production and glucose production yield, despite of using alkaline pretreatment or bioextrusion. The negative influence of the solid loading factor on the hydrolysis has been observed with other biomasses and batch conditions (Du et al., 2017; Geng et al., 2015).

315 production yield $(\sim 53 \%)$ were obtained with the alkaline pretreated biomass (Figures 5A and

316 B). These results are also fully compatible with the higher surface cellulose exposure (both

317 crystalline and amorphous) detected for PC biomass by FTCM-depletion assay (Figure 4).

318 Alkaline pretreatment has been shown to improves the enzymatic hydrolysis of biomass (Sun 319 and Cheng, 2002). Furthermore, there was no significant difference in the reducing sugar 320 production and glucose production yield between the non-bioextruded (PC-E) and 321 bioextruded (PC-XE) alkaline pretreated corn (Figures 5A and B). The efficiency of the 
pretreatment used in this study could explain the absence of impact from the additional

323 bioextrusion step. The efficient alkaline pretreatment highly improves the enzymatic accessibility thus strongly reducing the need for an additional biocatalyst impregnation step (bioextrusion).

3.2.4. Influence of the bioextrusion step.

In RC biomass, bioextrusion increased the total reducing sugar conversion by at least $94 \%$ (in the case of $14 \% \mathrm{~S} / \mathrm{L}$ ratio) for all $\mathrm{S} / \mathrm{L}$ ratio conditions (Figure $5 \mathrm{~A}$ ). The highest increase of $149 \%$ was seen in the case of $40 \% \mathrm{~S} / \mathrm{L}$ ratio. In the case of glucose production yield, bioextrusion increased the glucose production yield rates by at least $31 \%$ (in the case of $40 \% \mathrm{~S} / \mathrm{L}$ ratio) and the highest increase of $49 \%$ was observed for $\mathrm{S} / \mathrm{L}$ ratio of $31 \%$ (Figure 5B). The bioextrusion's positive influence on glucose production yield was less pronounced than on total reducing sugar conversion (Figures 5A and B). However, one must be aware that reducing sugar measurements are non-specific. DNS analysis also titrates poly/oligosaccharides and monosaccharides reducing ends obtained from hemicellulose hydrolysis. This may explain the observed differences between glucose conversion yield and total reducing sugars conversions. It should be noted that the maximal glucose conversion 338 yield achieved with bioextrusion (RC-XE) was $23 \%$ (in the case of $14 \% \mathrm{~S} / \mathrm{L}$ ratio) compared 339 to the mere $16 \%$ (in the case of $14 \% \mathrm{~S} / \mathrm{L}$ ratio) conversion yield measured for non 340 bioextrusion (RC-E) residues (Figure 5B), indicating that it did improve hydrolysis, although 341 much less efficiently than alkaline pretreatment ( 50\% glucose conversion yield). The

342 positive influence of bioextrusion on glucose production yield is clearly negatively influenced 343 by the solid loading but to a lesser extent than on reducing sugar conversion (Figures 5A and B).

Mixing the enzymes with biomass during mechanical treatment using the bioextrusion 346 technique appears to significantly improve the enzymatic hydrolysis of RC. These enhanced 
347 hydrolysis results can be associated with good bioextrusion dispersive and distributive mixing

348 conditions, especially by means of the kneading blocks. These characteristics can improve

349 mass transfer, agitation efficiency and allow higher contact between enzymes and substrate.

350 These significant improvements are obtained without high temperatures or strong chemicals

351 and with relatively very high solid loadings (up to $40 \%$ of S/L ratio). Bioextrusion positive

352 influence can be used as a way to increase the sugar production for a given substrate loading,

353 or as a way to retain good hydrolysis outcomes with higher substrate loadings and reduced

354 water consumption.

In the case of PC, comparable conversion rates were obtained with or without the

bioextrusion step (Figures 5A and B). This information highlights that the good mixing

conditions of the bioextrusion step did not afford any additional advantage when the intensive

alkaline pretreatment was used.

The proportion of dry mass loss after $48 \mathrm{~h}$ of enzymatic hydrolysis was measured and analyzed for biomass fractionation using particle size distribution for all reaction conditions conversion rates discussed above (Figures 5A and B).

It was apparent that increasing the $\mathrm{S} / \mathrm{L}$ ratio led to a diminished production of small particles (dry biomass smaller than $1.5 \mu \mathrm{m}$ ) (Figure 5C). This suggests that the deconstruction 
compared to RC-E. Indirectly, this explains the impact of bioextrusion on increased

373 enzymatic hydrolysis which is in agreement with reducing sugar conversion rates and glucose production yield (Figures 5A and B).

Furthermore, alkaline pretreated biomass exhibited maximum biomass fractionation when compared to raw biomass. Figure 5C shows that for PC-E and PC-XE the difference in terms of particle size distribution between 14 and $31 \%$ of $\mathrm{S} / \mathrm{L}$ ratios is relatively less pronounced than the difference in terms of conversion rates (Figures 5A and B). Moreover, a slight increase $(\sim 9 \%)$ of the proportion of particles under $1.5 \mu \mathrm{m}$ is observable for $31 \%$ of $\mathrm{S} / \mathrm{L}$ ratio for the PC-XE (Figure 5C). This may indicate a small improvement of the fractionation using the bioextrusion step even when an intense alkaline pretreatment step was used. a significant amount of unhydrolyzed biomass retained. Therefore, after hydrolysis (48 h) of various pretreated corn crop-residues, the unhydrolyzed components were tracked by FTCMdepletion assay. Figures 6 A-D represent crystalline and amorphous cellulose accessibility FTCM tests presented in Figure 6.

Figure 6. Surface accessibility profile of lignocellulosic components in corn crop residues after enzymatic $P C$. RC-E, raw corn without a previous bioextrusion step; $R C-X E$, raw corn with a previous bioextrusion step; $P C$-E, alkaline pretreated corn without bioextrusion; $P C$-XE, alkaline pretreated corn with previous 
The fiber surface exposure of raw biomass after batch hydrolysis was dominated by

401

402

403

404

405

406

407

408

409

410

411

412

413

414

415

416

417 crystalline cellulose (2.5-3 fold higher than amorphous cellulose) under all S/L ratio (Figure 6A). This indicates that in all cases, the exposed outer surface is mostly composed of crystalline cellulose and that $\mathrm{S} / \mathrm{L}$ ratio did not lead to preferential hydrolysis of either cellulose form. The dominance of crystalline cellulose in RC biomass is fully compatible with previously measured crystallinity indexes for raw corn crop residues (Kumar et al., 2009).

Cellulose accessibility profile of RC-E exhibited a gradual increment in both crystalline and amorphous cellulose with respect to the $\mathrm{S} / \mathrm{L}$ ratio (Figure 6A). This comparatively higher cellulose surface exposure is due to the inherent nature of enzymatic hydrolysis. Enzymatic hydrolysis is a layer by layer process i.e. after the complete hydrolysis of an exposed polysaccharide layer, a new, previously buried or hidden, layer with different surface characteristics will expose. In this case, after $48 \mathrm{~h}$ of enzymatic hydrolysis, it seems that in all the $\mathrm{S} / \mathrm{L}$ ratios a new polysaccharide layer with higher amount of both crystalline and amorphous cellulose is exposed. Furthermore, this increase in the surface cellulose exposure could also be related to the increase in the substrate loading. Higher substrate loading with limited enzyme supplementation or non-optimum reaction conditions is expected to leave behind a significant amount of unhydrolyzed substrate, thus increasing the detection of both crystalline and amorphous cellulose.

This suggests that enzymatic hydrolysis of RC biomass became more and more inefficient at higher $\mathrm{S} / \mathrm{L}$ ratio. The higher content in exposed cellulose left after hydrolysis is fully compatible with the decreased sugar conversion yield observed for higher S/L ratio (Figures 5A and B). The detection of larger content of exposed cellulose in higher S/L ratio appears to be a direct consequence of inability of enzyme to achieve efficient cellulose degradation in low water biomass. It also suggests that inefficient conversion at high $\mathrm{S} / \mathrm{L}$ ratio is not a result of lack of exposed cellulose, which was abundant under such conditions. 
Similar trends were observed regarding the cellulose accessibility profiles of RC-XE

426 biomass (Figure 6B). The amount of available cellulose at surface grew as the S/L ratio increased, corroborating sugar conversion yield indicating the negative impact of S/L ratio on enzymatic efficiency (figures 5A and B). Further, comparing results from panel A to panel B allows to emphasize the positive impact of bioextrusion on following batch hydrolysis.

Comparing to RC-E cellulose accessibility profile, both crystalline and amorphous cellulose accessibility in RC-XE biomass was at least 1.25 -fold lower at any given $\mathrm{S} / \mathrm{L}$ ratio. This is due to an additional bioextrusion pretreatment step which led to enhanced enzymatic hydrolysis of the corn crop residues biomass as discussed earlier (Figures 5A and B). Again, in the RC-XE biomass, the fiber surface exposure was dominated by crystalline cellulose. The amorphous cellulose exposure was 2.5-3-fold lower than crystalline cellulose, suggesting that $\mathrm{S} / \mathrm{L}$ ratio did not change cellulose populations (crystalline versus non-crystalline).

Figure $6 \mathrm{C}$ represents the cellulose accessibility profile of PC-E biomass. The result exhibits an important decrement in both crystalline and amorphous cellulose with respect to the $\mathrm{S} / \mathrm{L}$ ratio. The improved enzymatic hydrolysis is likely to have hydrolyzed most of the biomass, thus leaving behind significantly lower amount of unhydrolyzed cellulose. These observations are fully compatible with the results presented in Figures 5A and B showing that alkaline pretreatment lead to the highest sugar conversion yield. The fiber surface exposure in PC-E biomass was dominated by crystalline cellulose. On the other hand, very small amount of amorphous cellulose was detected by FTCM probes for PC-E which is due to the preferential vulnerability of disordered cellulose. In the case of PC-XE biomass (Figure 6D), FTCM probes indicate a further degradation of cellulose afforded by the addition of bioextrusion to alkaline pretreatment. This additional degradation corroborates results on particle size reduction where a slight increase $(\sim 9 \%)$ in percentage of small particles was observed for PC-E vs PC-XE (Figure 5C). However, the additional degradation suggested 
here remains small, and did not lead to significant increase in sugar production yield. In

451 summary, the FTCM-depletion assay strongly suggests that after $48 \mathrm{~h}$ of enzymatic hydrolysis

452 of RC biomass, there was still a substantial amount of unhydrolyzed cellulose left which

453 could be hydrolyzed by improving the enzyme concentration and/or hydrolysis time. This also

454 suggests that the FTCM-depletion assay could be used to characterize the unhydrolyzed

455 biomass for optimum enzymatic hydrolysis. Bioextrusion significantly reduced the

456 unhydrolyzed total cellulose amount which may be linked with good dispersive and

457 distributive mixing conditions, overcoming some limitations associated with high solid

458 loadings (Ramos et al., 2015) and biomass microstructure. Alkaline pretreatment led to a

459 strong reduction of unhydrolyzed total cellulose on the surface, which is compatible with

460 extended biomass deconstruction (Figure 5C) and hydrolysis (Figures 5A and B). The strong

461 alkaline pretreatment conditions led to a very limited influence of the previous bioextrusion

462 step. However, this finite influence was only detectable via FTCM-depletion assay.

\section{Industrial perspectives}

Bioextrusion demonstrated a significant improvement for the raw LCB valorization. In raw $\mathrm{LCB}$, this mild condition pretreatment proved to be efficient with very high substrate loadings (up to $40 \%$ of solid to liquid ratio) and allowed good hydrolysis conditions while increasing the substrate concentration. In addition, extrusion is a continuous process that is easily adaptable to industrial scale. Therefore, bioextrusion would be a viable option for industries to obtain concentrated sugars, especially for second generation bioethanol production, while keeping mild pretreatment conditions with a very limited impact of water consumption and removal.

However, the best hydrolysis outcomes were obtained with severe alkaline pretreatment, which seems to strongly reduce the positive influence of the bioextrusion step. This result supports the idea that the removal of the ligno-hemicellulosic barrier allows good enzymatic 
475

476

477

478

479

480

481

482

483

484

485

486

487

488

489

490

491

492

493

494

495

impregnation of the biomass even without bioextrusion. Nevertheless, LCB pretreatment is one of the costliest step in the biological production of cellulosic ethanol (about $20 \%$ of the total cost) (Yang and Wyman, 2008). Such a severe alkaline pretreatment, close to the conditions used in the paper industry, is not economically viable. This suggests that there is a challenge to find a milder alkaline pretreatment conditions which could go along with bioextrusion to improve the LCB hydrolysis with high solid loadings. Existing mild reactive extrusion pretreatments (Duque et al., 2017; Vandenbossche et al., 2016) could be a solution to limit the inhibiting side-effects of strong physico-chemical pretreatments, while allowing process continuity with bioextrusion.

Furthermore, FTCM-depletion assay allowed inspection of the cellulose accessibility profile for both raw and alkaline pretreated corn crop residues. Total cellulose accessibility was found to be higher for alkaline pretreated biomass. To our knowledge, this is the first time the FTCM methodology has helped to characterize the unhydrolyzed materials (after $48 \mathrm{~h}$ of enzymatic hydrolysis). Compare to alkaline pretreated biomass, the raw biomass exhibited significantly higher total cellulose accessibility in the unhydrolyzed biomass after $48 \mathrm{~h}$ of enzymatic hydrolysis. Moreover, it demonstrated that surface exposed cellulose was mainly in its crystalline (most resistant) form. The FTCM-depletion assay findings supported the information obtained with classical analytical techniques. FTCM-depletion assay may offer considerable potential to optimize and increase the overall performance of the biomass pretreatment strategies for biofuel production technologies.

\section{Conclusions}

The bioextrusion pretreatment enhanced the subsequent batch hydrolysis of raw corn crop residues at high solid loadings (solid/liquid ratio up to $40 \%$ ). The positive influence of bioextrusion was negatively influenced by the solid loading(s) The surface cellulose 
499

500

501

502

503

504

505

506

507

508

509

510

511

512

513

514

515

516

517

518

519

520

accessibility analysis via FTCM-depletion assay supported classical analyses and exhibited that the negative impact of high solid/liquid ratio on conversion yield were not associated with a lack of exposed cellulose. Bioextrusion was found to be less efficient on severe alkaline pretreated biomass but being a mild and solvent limiting pretreatment technique, it might help to decrease the pretreatment waste stream.

\section{Acknowledgments}

The French Ministry of Higher Education and Research (MESR) and the Institut National Polytechnique of Toulouse (INPT) are gratefully acknowledged for the financial support allocated to this project. The authors would also like to thank the European Community Seventh Framework Program under Grant agreement reference no 227498 (BABETHANOL PROJECT) that partially funded previous researches that have led to this work. We would like to thank Dr. Kokou Adjallé for his expert and technical assistance while performing the enzymatic hydrolysis. Buckman Laboratories International, Inc. has filed patent applications in several countries on FTCM methodology.

(1)

(1)


1. Adjalle, K., Larose, L.-V., Bley, J., Barnabé, S., 2017. The effect of organic nitrogenous compound content and different pretreatments on agricultural lignocellulosic biomass characterization methods. Cellulose 24, 1395-1406. https://doi.org/10.1007/s10570-017-1199-8

2. Arantes, V., Saddler, J.N., 2010. Access to cellulose limits the efficiency of enzymatic hydrolysis: the role of amorphogenesis. Biotechnol. Biofuels 3, 4 . https://doi.org/10.1186/1754-6834-3-4

3. Bombeck, P.-L., Khatri, V., Meddeb-Mouelhi, F., Montplaisir, D., Richel, A., Beauregard, M., 2017. Predicting the most appropriate wood biomass for selected industrial applications: comparison of wood, pulping, and enzymatic treatments using fluorescent-tagged carbohydrate-binding modules. Biotechnol. Biofuels 10. https://doi.org/10.1186/s13068-017-0980-0

4. Boonsombuti, A., Luengnaruemitchai, A., Wongkasemjit, S., 2013. Enhancement of enzymatic hydrolysis of corncob by microwave-assisted alkali pretreatment and its effect in morphology. Cellulose 20, 1957-1966. https://doi.org/10.1007/s10570-0139958-7

5. Chouvel, H., Chay, P., Cheftel, J., 1983. Enzymatic hydrolysis of starch and cereal flours at intermediate moisture contents in a continuous extrusion-reactor. Lebensm.Wiss. Technol. Food Sci. Technol.

6. Danisco US Inc., 2007. Accelerase 1000 - Cellulase enzyme complex for lignocellulosic biomass hydrolysis - Technical bulletin no.1 : saccharification.

7. DeMartini, J.D., Pattathil, S., Miller, J.S., Li, H., Hahn, M.G., Wyman, C.E., 2013. Investigating plant cell wall components that affect biomass recalcitrance in poplar and switchgrass. Energy Environ. Sci. 6, 898-909. https://doi.org/10.1039/C3EE23801F

8. Du, J., Cao, Y., Liu, G., Zhao, J., Li, X., Qu, Y., 2017. Identifying and overcoming the effect of mass transfer limitation on decreased yield in enzymatic hydrolysis of lignocellulose at high solid concentrations. Bioresour. Technol. 229, 88-95. https://doi.org/10.1016/j.biortech.2017.01.011

9. Duque, A., Manzanares, P., Ballesteros, I., Negro, M.J., Oliva, J.M., González, A., Ballesteros, M., 2014. Sugar production from barley straw biomass pretreated by combined alkali and enzymatic extrusion. Bioresour. Technol. 158, 262-268. https://doi.org/10.1016/j.biortech.2014.02.041

10. Fan, L., Gharpuray, M.M., Lee, Y.-H., 1987. Enzymatic Hydrolysis, in: Cellulose Hydrolysis, Biotechnology Monographs. Springer, Berlin, Heidelberg, pp. 21-119. https://doi.org/10.1007/978-3-642-72575-3_3

11. Gatt, E., Rigal, L., Vandenbossche, V., 2018. Biomass pretreatment with reactive extrusion using enzymes: A review. Ind. Crops Prod. 122, 329-339. https://doi.org/10.1016/j.indcrop.2018.05.069

12. Geng, W., Jin, Y., Jameel, H., Park, S., 2015. Strategies to achieve high-solids enzymatic hydrolysis of dilute-acid pretreated corn stover. Bioresour. Technol. 187, 43-48. https://doi.org/10.1016/j.biortech.2015.03.067

13. Ghose, T., 1987. Measurement of cellulase activities. Pure Appl. Chem. 59, 257-268.

14. Govindasamy, S., Campanella, O.H., Oates, C.G., 1997. Enzymatic hydrolysis of sago starch in a twin-screw extruder. J. Food Eng. 32, 403-426. https://doi.org/10.1016/S0260-8774(97)00017-4

15. Hébert-Ouellet, Y., Meddeb-Mouelhi, F., Khatri, V., Cui, L., Janse, B., MacDonald, K., Beauregard, M., 2017. Tracking and predicting wood fibers processing with fluorescent carbohydrate binding modules. Green Chem. 19, 2603-2611. https://doi.org/10.1039/C6GC03581G

16. Himmel, M.E., Ding, S.-Y., Johnson, D.K., Adney, W.S., Nimlos, M.R., Brady, J.W., Foust, T.D., 2007. Biomass Recalcitrance: Engineering Plants and Enzymes for Biofuels Production. Science 315, 804-807. https://doi.org/10.1126/science.1137016 
17. Hodge, D.B., Karim, M.N., Schell, D.J., McMillan, J.D., 2008. Soluble and insoluble solids contributions to high-solids enzymatic hydrolysis of lignocellulose. Bioresour. Technol. 99, 8940-8948. https://doi.org/10.1016/j.biortech.2008.05.015

18. Hong, J., Ye, X., Zhang, Y.-H.P., 2007. Quantitative Determination of Cellulose Accessibility to Cellulase Based on Adsorption of a Nonhydrolytic Fusion Protein Containing CBM and GFP with Its Applications. Langmuir 23, 12535-12540. https://doi.org/10.1021/la7025686

19. Karunanithy, C., Muthukumarappan, K., 2013. Thermo-Mechanical Pretreatment of Feedstocks, in: Gu, T. (Ed.), Green Biomass Pretreatment for Biofuels Production. Springer Netherlands, Dordrecht, pp. 31-65.

20. Khatri, V., Hébert-Ouellet, Y., Meddeb-Mouelhi, F., Beauregard, M., 2016. Specific tracking of xylan using fluorescent-tagged carbohydrate-binding module 15 as molecular probe. Biotechnol. Biofuels 9, 74. https://doi.org/10.1186/s13068-0160486-1

21. Khatri, V., Meddeb-Mouelhi, F., Adjallé, K., Barnabé, S., Beauregard, M., 2018a. Determination of optimal biomass pretreatment strategies for biofuel production: investigation of relationships between surface-exposed polysaccharides and their enzymatic conversion using carbohydrate-binding modules. Biotechnol. Biofuels 11, 144. https://doi.org/10.1186/s13068-018-1145-5

22. Khatri, V., Meddeb-Mouelhi, F., Beauregard, M., 2018b. New insights into the enzymatic hydrolysis of lignocellulosic polymers by using fluorescent tagged carbohydrate-binding modules. Sustain. Energy Fuels 2, 479-491. https://doi.org/10.1039/C7SE00427C

23. Kim, I., Rehman, M.S.U., Han, J.-I., 2014. Enhanced glucose yield and structural characterization of corn stover by sodium carbonate pretreatment. Bioresour. Technol. 152, 316-320. https://doi.org/10.1016/j.biortech.2013.10.069

24. Kim, J.S., Lee, Y.Y., Kim, T.H., 2016. A review on alkaline pretreatment technology for bioconversion of lignocellulosic biomass. Bioresour. Technol., Pretreatment of Biomass 199, 42-48. https://doi.org/10.1016/j.biortech.2015.08.085

25. Kim, Y., Hendrickson, R., Mosier, N.S., Ladisch, M.R., Bals, B., Balan, V., Dale, B.E., 2008. Enzyme hydrolysis and ethanol fermentation of liquid hot water and AFEX pretreated distillers' grains at high-solids loadings. Bioresour. Technol., Cellulose Conversion in Dry Grind Plants 99, 5206-5215. https://doi.org/10.1016/j.biortech.2007.09.031

26. Kumar, R., Mago, G., Balan, V., Wyman, C.E., 2009. Physical and chemical characterizations of corn stover and poplar solids resulting from leading pretreatment technologies. Bioresour. Technol. 100, 3948-3962. https://doi.org/10.1016/j.biortech.2009.01.075

27. Lee, J.W., Kim, J.Y., Jang, H.M., Lee, M.W., Park, J.M., 2015. Sequential dilute acid and alkali pretreatment of corn stover: Sugar recovery efficiency and structural characterization. Bioresour. Technol. 182, 296-301. https://doi.org/10.1016/j.biortech.2015.01.116

28. Lin, Y., Tanaka, S., 2006. Ethanol fermentation from biomass resources: current state and prospects. Appl. Microbiol. Biotechnol. 69, 627-642. https://doi.org/10.1007/s00253-005-0229-x

29. Lynd, L.R., 2017. The grand challenge of cellulosic biofuels. Nat. Biotechnol. 35, 912.

30. Lynd, L.R., Wyman, C.E., Gerngross, T.U., 1999. Biocommodity Engineering. Biotechnol. Prog. 15, 777-793. https://doi.org/10.1021/bp990109e

31. Mansfield, S.D., Mooney, C., Saddler, J.N., 1999. Substrate and Enzyme Characteristics that Limit Cellulose Hydrolysis. Biotechnol. Prog. 15, 804-816. https://doi.org/10.1021/bp9900864

32. Ramachandriya, K.D., Wilkins, M., Atiyeh, H.K., Dunford, N.T., Hiziroglu, S., 2013. Effect of high dry solids loading on enzymatic hydrolysis of acid bisulfite pretreated Eastern redcedar. Bioresour. Technol. 147, 168-176. https://doi.org/10.1016/j.biortech.2013.08.048 
33. Ramos, L.P., da Silva, L., Ballem, A.C., Pitarelo, A.P., Chiarello, L.M., Silveira, M.H.L., 2015. Enzymatic hydrolysis of steam-exploded sugarcane bagasse using high total solids and low enzyme loadings. Bioresour. Technol. 175, 195-202. https://doi.org/10.1016/j.biortech.2014.10.087

34. Rollin, J.A., Zhu, Z., Sathitsuksanoh, N., Zhang, Y.-H.P., 2011. Increasing cellulose accessibility is more important than removing lignin: A comparison of cellulose solvent-based lignocellulose fractionation and soaking in aqueous ammonia. Biotechnol. Bioeng. 108, 22-30. https://doi.org/10.1002/bit.22919

35. Samaniuk, J.R., Tim Scott, C., Root, T.W., Klingenberg, D.J., 2011. The effect of high intensity mixing on the enzymatic hydrolysis of concentrated cellulose fiber suspensions. Bioresour. Technol. 102, 4489-4494. https://doi.org/10.1016/j.biortech.2010.11.117

36. Sluiter, A., Hames, B., Ruiz, R., Scarlata, C., Sluiter, J., Templeton, D., others, 2010. Determination of structural carbohydrates and lignin in biomass: laboratory analytical procedure (LAP). Golden, CO: National Renewable Energy Laboratory; 2008 April. NREL Report No. Contract No -AC36-99-G010337 Spons. US Dep. Energy.

37. Song, X., Jiang, Y., Rong, X., Wei, W., Wang, S., Nie, S., 2016. Surface characterization and chemical analysis of bamboo substrates pretreated by alkali hydrogen peroxide. Bioresour. Technol. 216, 1098-1101. https://doi.org/10.1016/j.biortech.2016.06.026

38. Sun, Y., Cheng, J., 2002. Hydrolysis of lignocellulosic materials for ethanol production: a review. Bioresour. Technol. 83, 1-11. https://doi.org/10.1016/S09608524(01)00212-7

39. Van Soest, P.J., Wine, R.H., 1968. Determination of lignin and cellulose in aciddetergent fiber with permanganate. J. Assoc. Off. Anal. Chem. 51, 780-785.

40. Vandenbossche, V., Brault, J., Vilarem, G., Hernández-Meléndez, O., Vivaldo-Lima, E., Hernández-Luna, M., Barzana, E., Duque, A., Manzanares, P., Ballesteros, M., Mata, J., Castellón, E., Rigal, L., 2014. A new lignocellulosic biomass deconstruction process combining thermo-mechano chemical action and bio-catalytic enzymatic hydrolysis in a twin-screw extruder. Ind. Crops Prod. 55, 258-266. https://doi.org/10.1016/j.indcrop.2014.02.022

41. Vandenbossche, V., Brault, J., Vilarem, G., Rigal, L., 2015. Bio-catalytic action of twin-screw extruder enzymatic hydrolysis on the deconstruction of annual plant material: Case of sweet corn co-products. Ind. Crops Prod. 67, 239-248. https://doi.org/10.1016/j.indcrop.2015.01.041

42. Wyman, C.E., 2013. Aqueous Pretreatment of Plant Biomass for Biological and Chemical Conversion to Fuels and Chemicals. John Wiley \& Sons.

43. Yang, B., Wyman, C.E., 2008. Pretreatment: the key to unlocking low-cost cellulosic ethanol. Biofuels Bioprod. Biorefining 2, 26-40. https://doi.org/10.1002/bbb.49

44. Zhang, Y.-H.P., Lynd, L.R., 2006. A functionally based model for hydrolysis of cellulose by fungal cellulase. Biotechnol. Bioeng. 94, 888-898. https://doi.org/10.1002/bit.20906

45. Zhang, Y.-H.P., Lynd, L.R., 2004. Toward an aggregated understanding of enzymatic hydrolysis of cellulose: Noncomplexed cellulase systems. Biotechnol. Bioeng. 88, 797-824. https://doi.org/10.1002/bit.20282 
Substrate Enzymes Buffer

\begin{tabular}{|c|c|c|c|c|c|c|c|c|c|c|c|c|c|c|c|c|c|c|c|c|c|}
\hline 60 & 60 & 40 & 30 & 20 & $\begin{array}{c}+ \\
45^{\circ}\end{array}$ & $\begin{array}{c}+ \\
45^{\circ} \\
\end{array}$ & \begin{tabular}{|c|c}
+ \\
$90^{\circ}$
\end{tabular} & 40 & 30 & \begin{tabular}{|c|}
+ \\
$45^{\circ}$ \\
\end{tabular} & \begin{tabular}{|c|c}
+ & + \\
$90^{\circ}$ & $90^{\circ}$
\end{tabular} & 40 & 20 & \begin{tabular}{|c|c|}
+ & + \\
$45^{\circ}$ & $90^{\circ}$ \\
\end{tabular} & 40 & 20 & & \begin{tabular}{|c|}
+ \\
$90^{\circ}$
\end{tabular} & 40 & 40 & 20 \\
\hline 45 & 45 & 90 & 90 & 90 & 30 & 30 & 30 & 90 & 90 & 30 & \begin{tabular}{|l|l|l} 
& 30 & 30
\end{tabular} & 90 & 90 & 3030 & 30 & 90 & 30 & 30 & 90 & 90 & 20 \\
\hline & & & & & & $\mathbf{M}$ & & & & & $\mathbf{M}$ & & & $\mathbf{M}$ & & $\mathbf{T}$ & $\mathbf{N}$ & $\mathbf{M}$ & & & \\
\hline
\end{tabular}




\section{\begin{tabular}{|l|l|}
\hline RC or $\mathrm{PC}$ & Buffer \\
\hline
\end{tabular}}

तु $ת$

After $48 \mathrm{~h}$

of

hydrolysis

\section{XE}

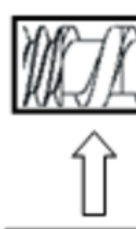

Enzymes

RC or PC+ Enzymes + Buffer

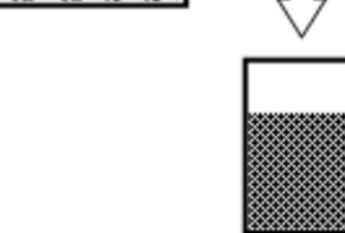

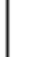

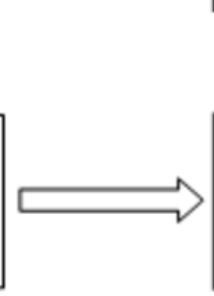

(B)

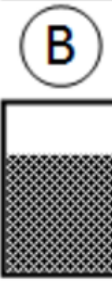

Enzymes deactivation

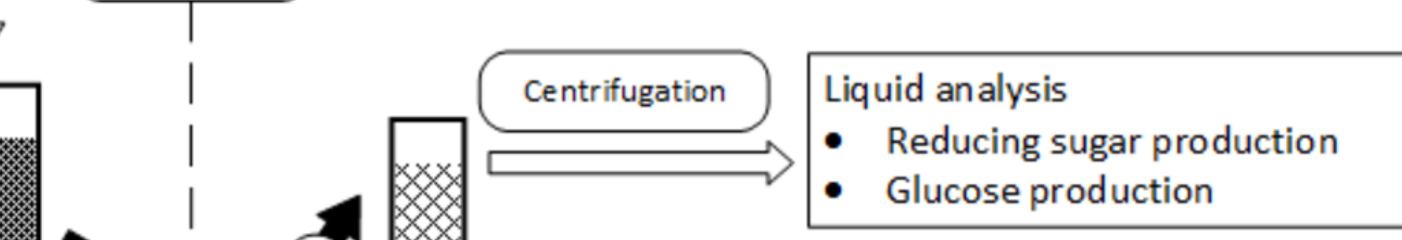

(1) $x$
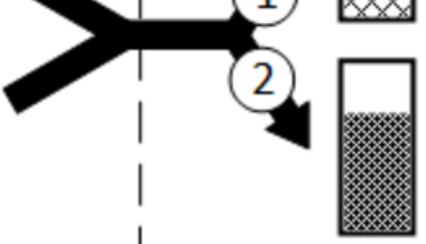

Filtration

+ Drying

\section{Solid analysis}

- Particule size distribution (dry mass loss during filtration)

- Crystalline and amorphous cellulose exposure analysis via FTCM-depletion assay 


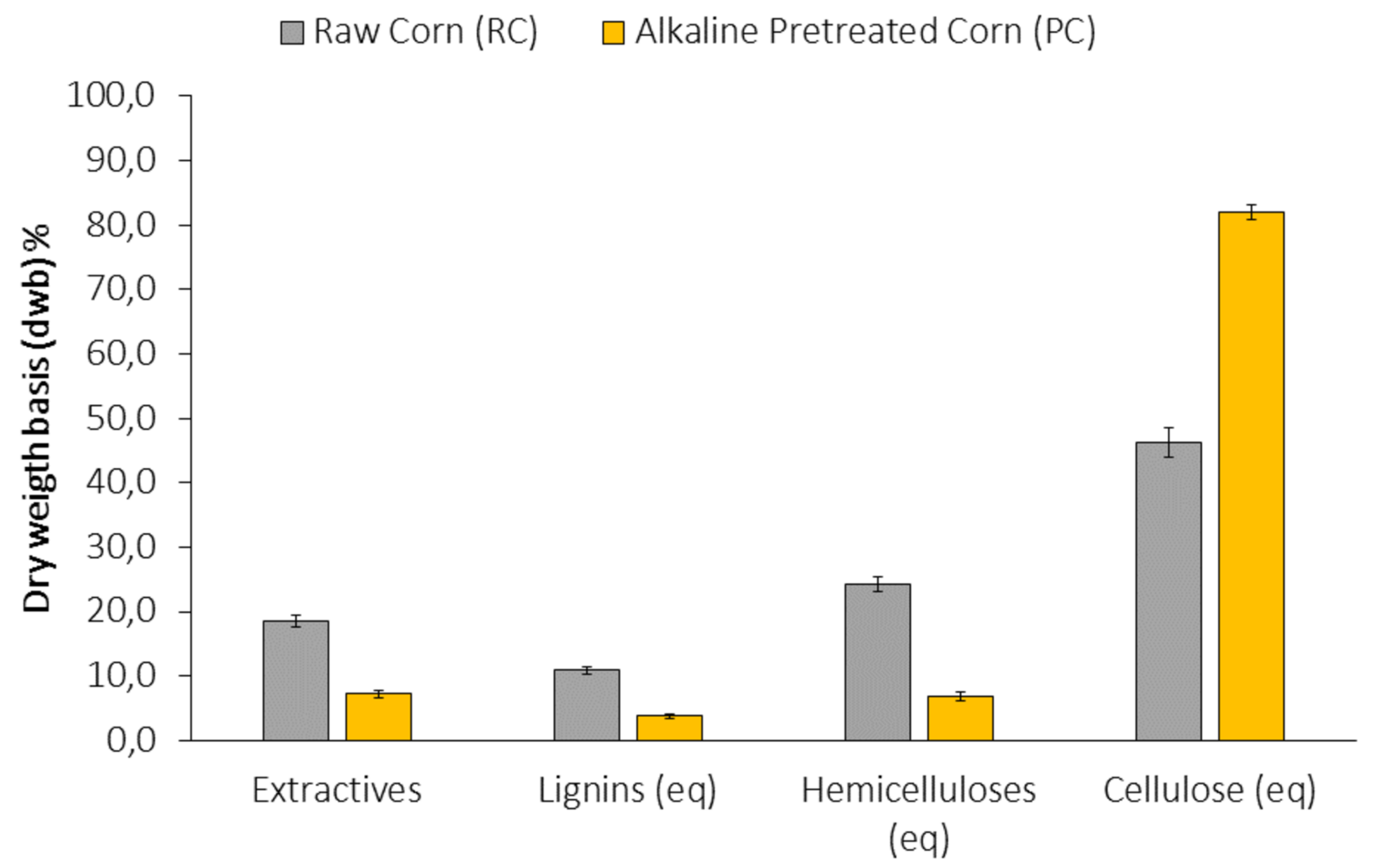


$\diamond \mathrm{RC}-\mathrm{E} \quad \triangle \mathrm{RC}-\mathrm{XE} \quad \diamond \mathrm{PC}-\mathrm{E} \quad \Delta \mathrm{PC}-\mathrm{XE}$

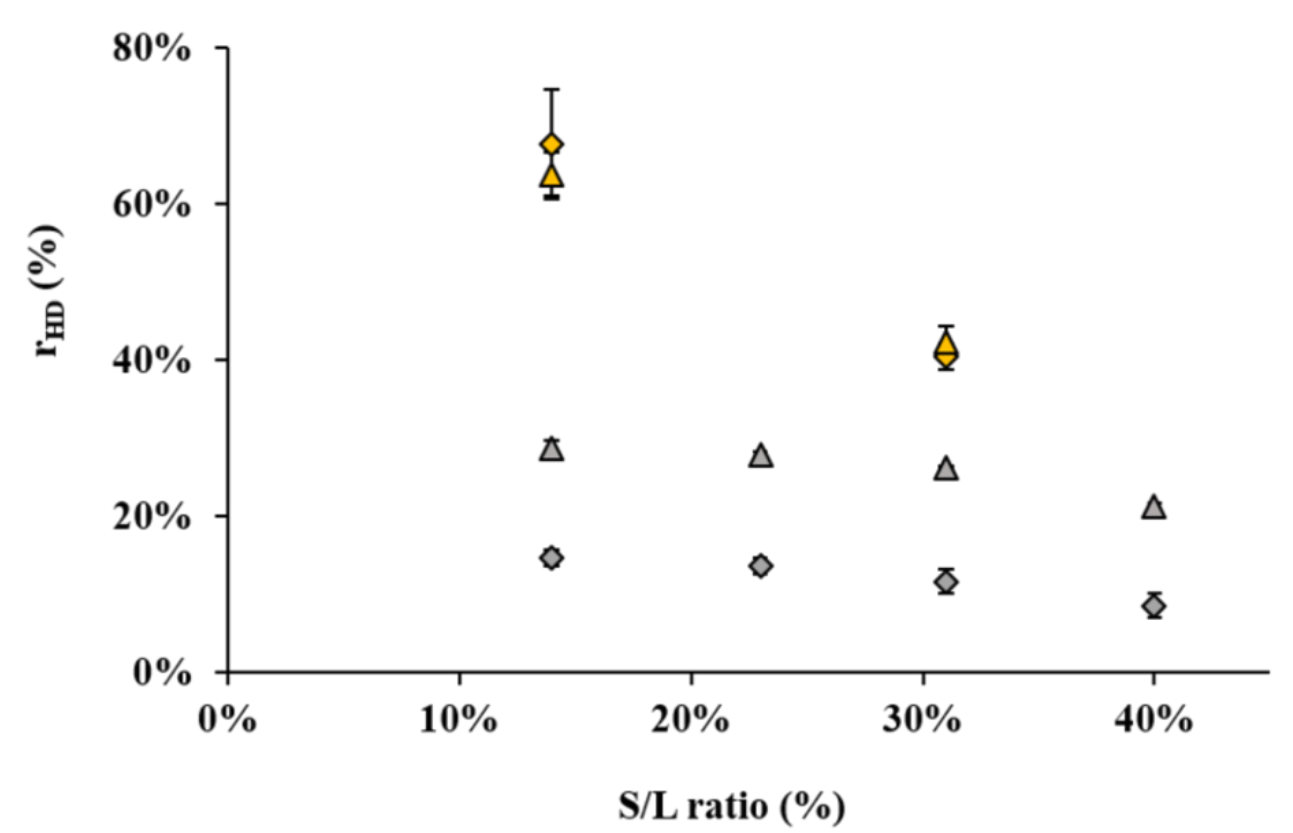

B

$\diamond$ RC-E $\triangle$ RC-XE $\diamond$ PC-E $\triangle$ PC-XE

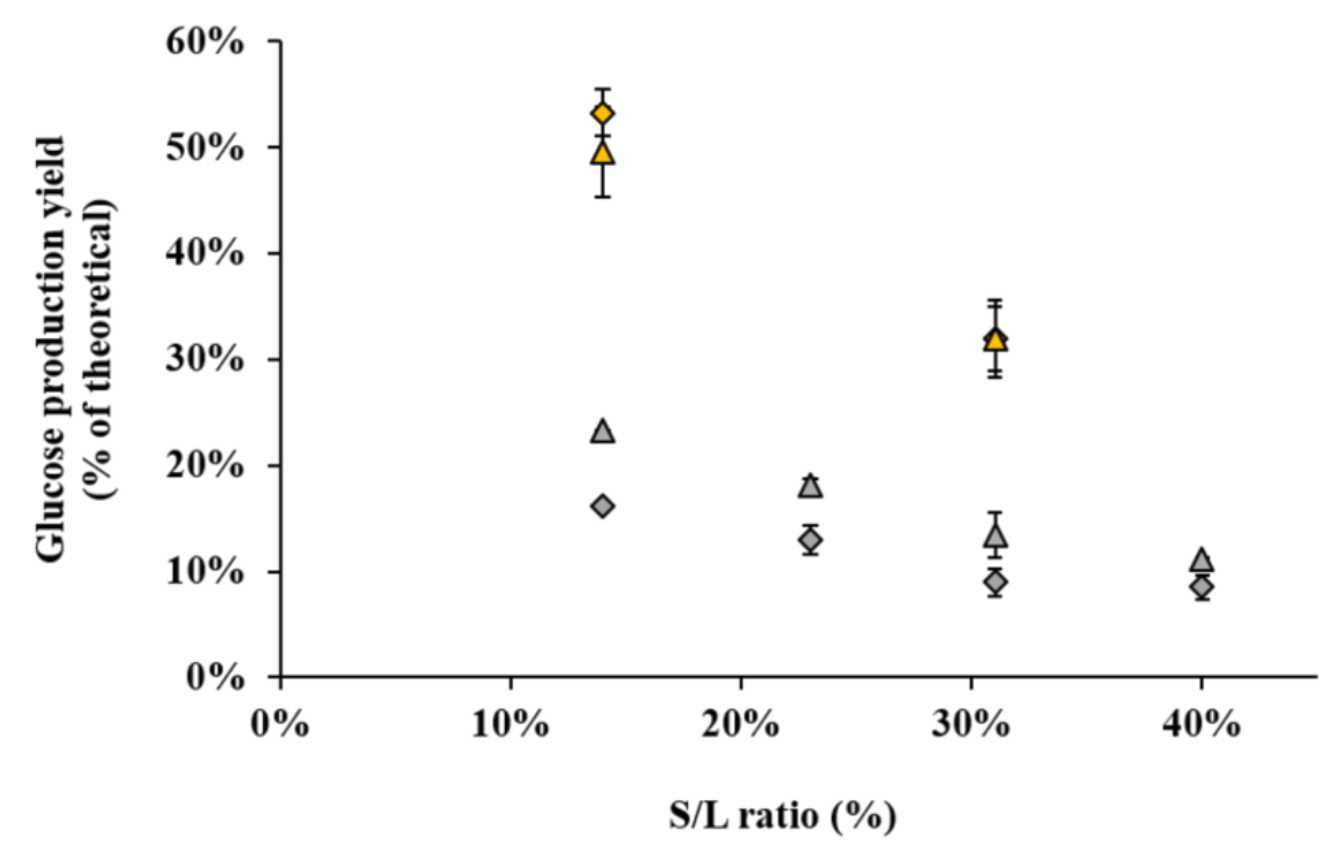

C

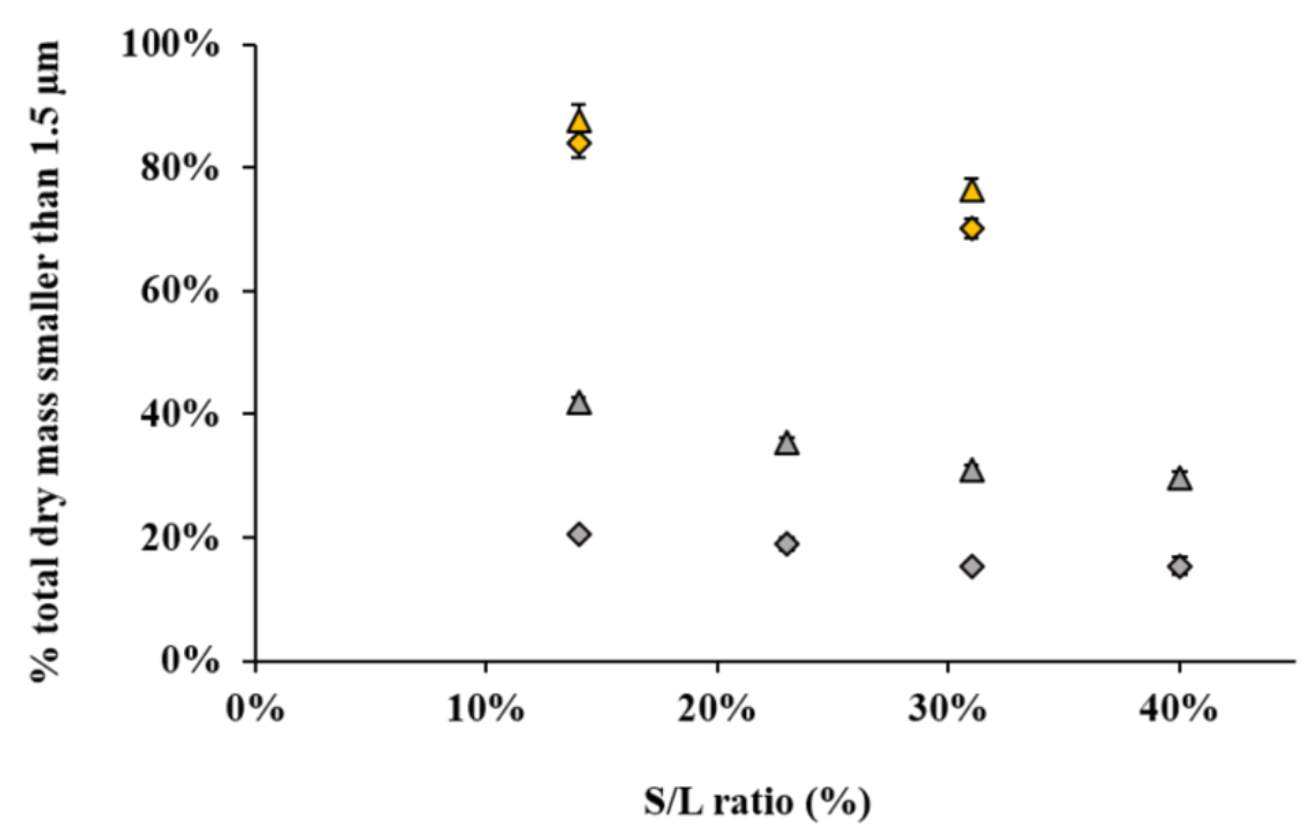



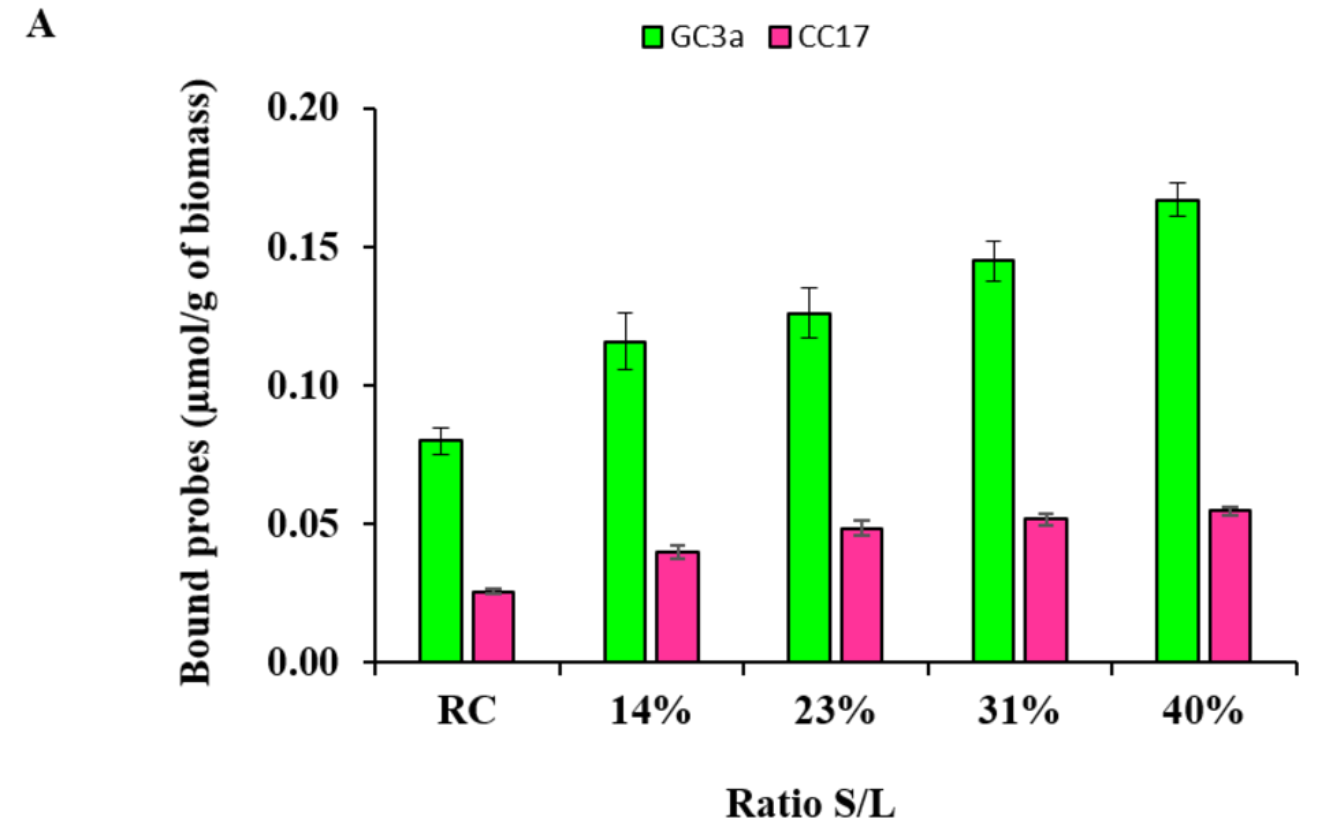

C

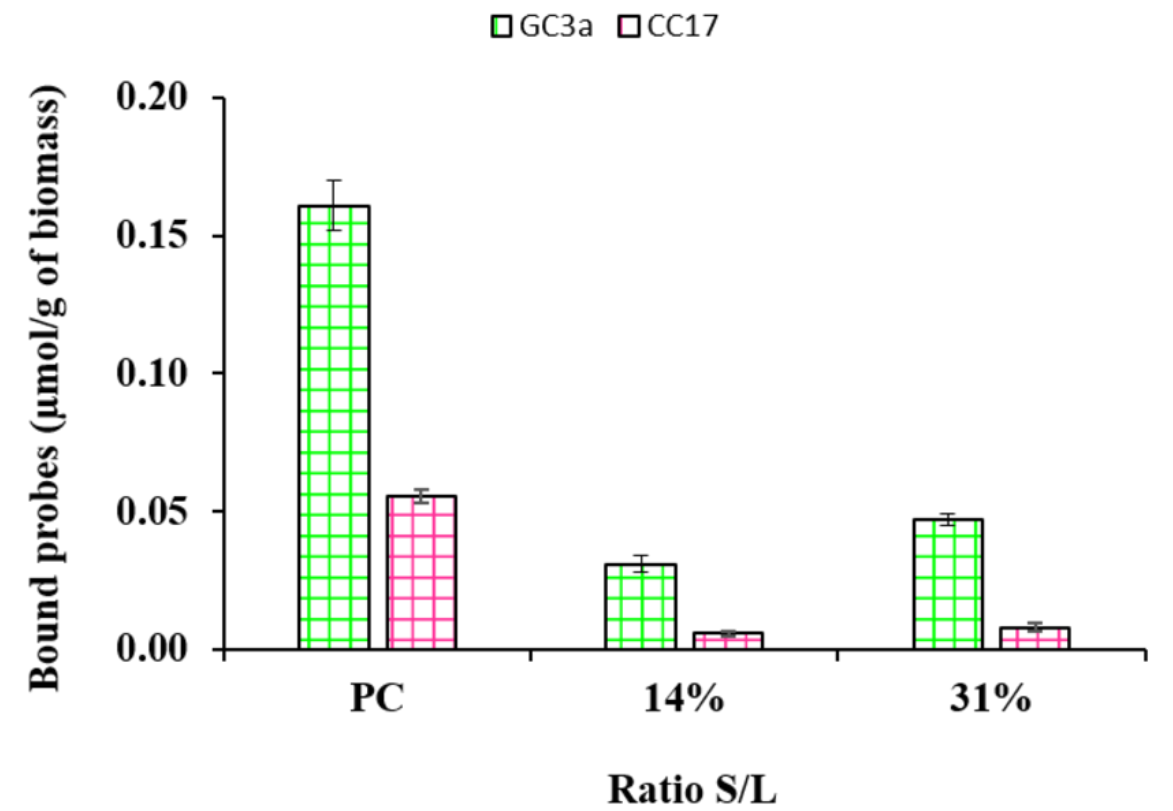

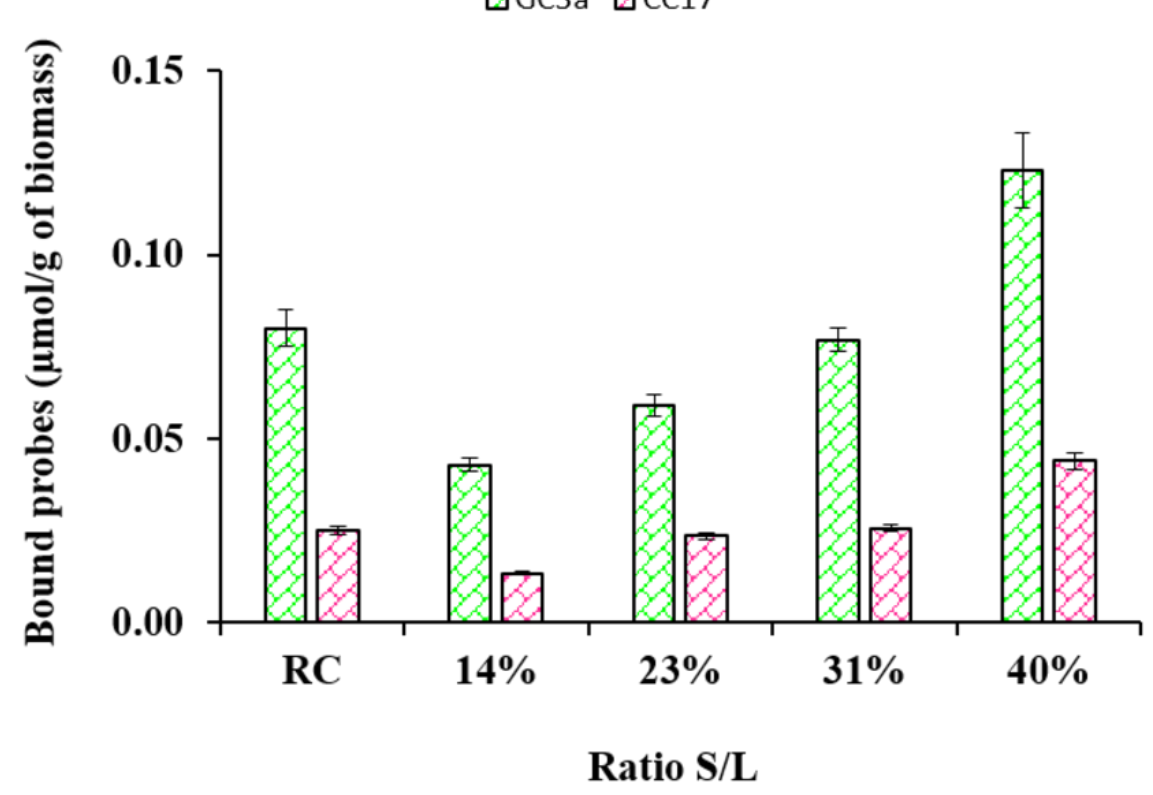

D

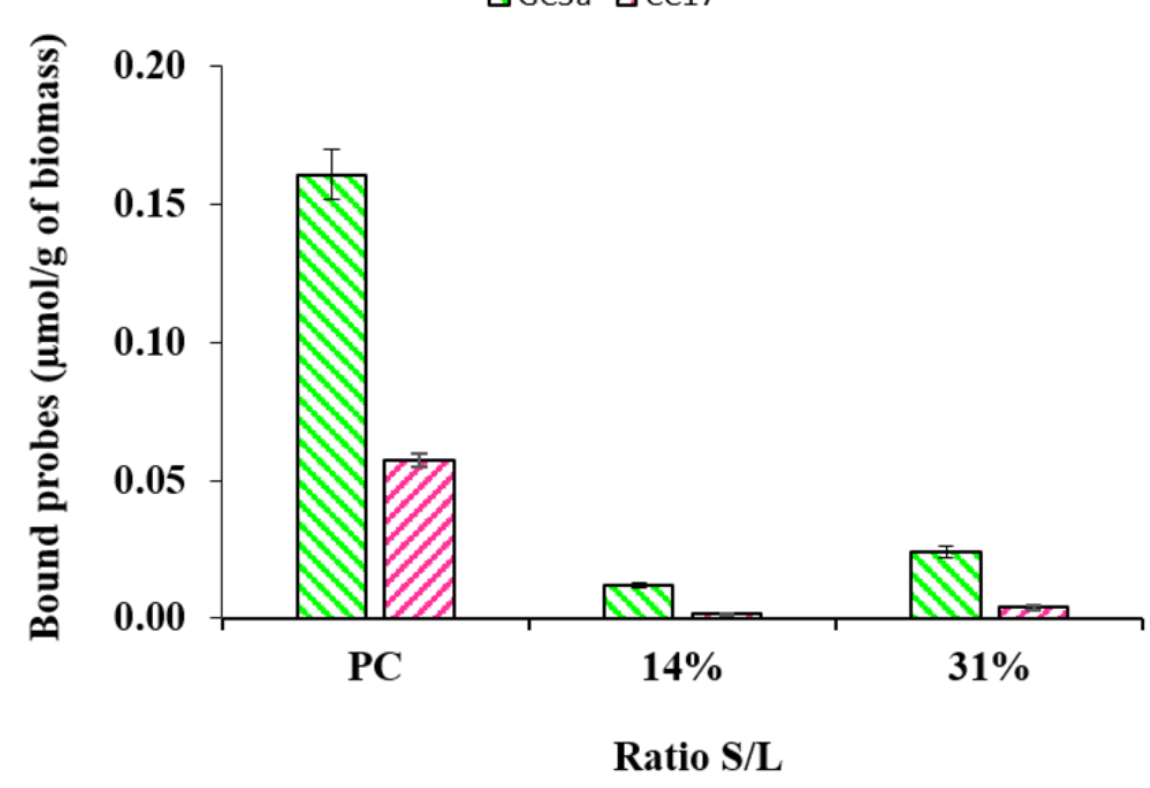

